\title{
Leninin Imperialismi-teoksen syntyhistoriaa
}

\section{Jukka Gronow}

Keväällä 1916 Maksim Gorki ehdotti Pariisissa asuvalle venäläiselle historioitsijalle, $M$. N. Pokrovskille, että tämä toimittaisi ulkomailla asuvien venäläisten asiantuntijoiden kanssa kirjasarjan "Eurooppa ennen sotaa ja sodan aikana". Sarjan tarkoituksena oli antaa "mahdollisimman laajalle lukijakunnalle" (lue: työläisille) käsitys käynnissä olevan sodan todellisesta luonteesta. Pokrovskin mukaan sarjaa ryhdyttiin innokkaasti suunnittelemaan: Lunatšarski sai tehtäväkseen kirjoittaa Italiasta, Zinovjev Itävalta-Unkarista ja Pokrovskin oli määrä kirjoittaa Ranskasta. Myös Englannista ja Saksasta oli suunnitteilla oma kirjansa. ${ }^{1}$ Sarjan yleisjohdannon kirjoittaminen annettiin Leninin tehtäväksi.

Leninin käsikirjoitus valmistui keväällä 1916. Se oli otsikoitu "Imperialismi kapitalismin korkeimpana vaiheena". Koska Lenin arveli, että teoksen nimi voisi aiheuttaa vaikeuksia Venäjän sensuurissa, hän ehdotti vaihtoehtoiseksi nimeksi "Uusimman kapitalismin keskeiset erikoispiirteet". Teos ilmestyi vasta helmikuun vallankumouksen jälkeen menshevikkien hallussa olleen Parus-kustantamon kautta nimellä "Imperialismi kapitalismin uusimpana vaiheena. Yleistajuinen esitys". Kustantajan toimesta Leninin tekstiin oli tehty useita muutoksia. 2 Alkuperäisessä muodossaan kirja ilmestyi vasta Lokakuun vallankumouksen jälkeen. 3

Leninin Imperialismi-teoksen nimenmuutokset antaisivat tuskin aihetta muuhun kuin bibliografiseen tarkasteluun, ellei niitä olisi käytetty tukemaan erilaisia käsityskantoja teoksen merkityksestä ja luonteesta. On väitetty "uusimman vaiheen" paremmin vastanneen Leninin intentioita, ja nimen muuttuneen "korkeimmaksi vaiheeksi"' vasta myöhemmin (Dutschke).3a "Uusin vaihe" viittaisi tämän mukaan vain kapitalismin erityiseen venäläiseen kehitysvaiheeseen, kun taas "korkein vaihe" viittaa selvemmin siihen, että imperialismi olisi myös kapitalismin viimeinen vaihe.
Jos tutustuu Leninin teokseen sen nimeä pidemmälle ei kuitenkaan - olipa alkuperäisen nimen laita sitten miten tahansa - voi jäädä epäselväksi, että Lenin tarkoitti imperialismilla todella kapitalismin korkeinta ja viimeistä vaihetta. Lenin toteaa esimerkiksi Imperialismi-teoksen alkulauseessa: "Siitä, että imperialismi on sosialistisen vallankumouksen aatto, ... - kaikesta tuota jouduin puhumaan 'orjan' kielellä, ..." 4 Monet Leninin sekä Imperialismi-teosta edeltäneet että sitä seuranneet kirjoitukset osoittavat myös, että Lenin tarkasteli imperialismia todella kapitalismin viimeisenä vaiheena, josta voidaan siirtyä vain sosialismiin. ${ }^{5}$

\section{1.}

Ensimmäisen kerran käsitys imperialismista kapitalismin erityisenä kehitysvaiheena esiintyy Leninin kirjoituksessa "Sota ja venäläinen sosialidemokratia" vuodelta $1914 .^{6}$ Lenin oli kuitenkin jo vuosisadan vaihteessa tarkastellut tuotannon keskittymistä ja siitä syntyvien monopolien vaikutusta kapitalismin kehitykseen.

1. Kaikki sarjaan suunnitellut osat julkaistiin ja niistä on otettu uusia painoksia neuvostovallan aikana.

2. Lenin, V. I., Valitut teokset neljässä osassa (LV). Edistys, Moskova 1967. Osa 2, s. 478.

3. Leninin Imperialismi-teoksen syntyvaiheista ks. esim. Pokrovski, M. N., Kak roždalsa 'Imperializm', teoksessa Vospominanije o Lenine. T. 3. Moskva 1960 , s. 132-135; Leontjev, L. A., Leninskaja teorija imperializma. Moskva 1969, s. 55-57;Jevzerov, P., Iz istorii sozdanija velikogo truda (K 60-letiju raboty V. I. Lenina "Imperializm kak vyšaja stadija kapitalizma), Mirovaja ekonomika i meždunarodnyje otnošenija, 6. 1976, s. $29-41$.

3a. Dutschke, Rudi, Versuch Lenin auf die Füsse zu stellen, Verlag Klaus Vagenbach Berlin 1974, s. 244.

4. LV, osa 2 ,s. 333 .

5. Ks. esim. Lenin, V. I., Teokset (LT). Suomennos neljännestä venäjänkielisestä painoksesta. Karjalais-suomalaisen SNT:n valtion kustannusliike, Petroskoi \& Kustannusliike Edistys, Moskova, 1953-1970. Osa 22 , s. 100 ; 135 ; osa 23 , s. 100 ; osa 24 , s. $455-456$; osa 25 , s. 447.

6. Vasilevski, E. G., Razvitije vzgljadov V. I. Lenina na imperializm. Izd. Moskovskogo universiteta 1969 , s. 89 . 
Ensimmäisissä asiaa koskevissa kirjoituksissa käsitellään mm. monopolien vaikutusta kapitalismin kriisikehitykseen, josta Lenin toteaa, että vaikka monopolit muuttavat kriisien ilmenemistä ne eivät kuitenkaan voi niitä lakkauttaa. Sama kysymys on tärkeä monissa myöhemmissäkin Leninin monopoleja käsittelevissä kirjoituksissa. Erityisesti vuoden 1905 jälkeen Lenin tutki konkreettisesti teollisuuden keskittymistä niin Venäjällä kuin muuallakin Euroopassa ja Yhdysvalloissa. Edelleen Lenin julkaisi kirjoituksia, jotka käsittelivät finanssipääomaa, maailmanlaajuisia syndikaatteja sekä monopolien ja valtion yhteenkietoutumista. Vuonna 1915 ilmestyneestä kirjoituksesta "Sosialismi ja sota" voidaan jo löytää lähes kaikki samat imperialismin perustunnusmerkit kuin Imperialismi-teoksestakin: imperialismi on kapitalismin korkein vaihe, joka on tullut hallitsevaksi vasta 20 . vuosisadalla; pääomien keskittyminen on johtanut siihen, että kokonaiset teollisuudenalat ovat syndikaattien ja trustien hallinnassa; kapitalistien yhteenliittymät ovat jakaneet lähes koko maapallon keskenään ja alistaneet maat finanssiriistolle; vapaa kauppa ja kilpailu ovat muuttuneet monopoliksi; kansainvälisessä kaupassa on tärkeäksi tullut pääomien vienti; kansojen vapauttajasta, jollainen kapitalismi oli taistellessaan feodalismia vastaan, kapitalismi on muuttunut kansojen sortajaksi.7 Ryhtyessään keväällä 1916 kirjoittamaan Imperialismiteostaan Lenin asetti tehtäväkseen imperialismin taloudellisen olemuksen paljastamisen. Tämä Leninin paljastama imperialismin taloudellinen olemus on monopoli.

Leninin Imperialismi-tutkimus liittyy vuosisadan vaihteen vilkkaaseen keskusteluun kartelleista, trusteista, siirtomaiden riistosta, pääomien viennistä ja raaka-ainelähteiden valtauksista, jota kävivät niin marxilaiset kuin porvarillisetkin tutkijat. Lenin nojautuikin tutkimuksessaan laajaan tilastoaineistoon ja lukuisiin porvarillisiin tutkimuksiin. Voidaan kuitenkin mainita neljä tutkijaa ja teosta, joilla on ollut ehkä muita enemmän vaikutusta Leninin imperialismia koskevien käsitysten syntymiseen: Rudolf $\mathrm{Hi}$ if e rding in Das Finanzkapital, Rosa Lux e mburgin Die Akkumulation des Kapitals, Karl Ka u ts k y n Nationalstaat, imperialistischer Staat und Staatsbund (sekä Kautskyn muut imperialismia koskevat kirjoitukset, esim. artikkeli Imperialismus) ja J. Ho b s o $\mathbf{n}$ in Imperialism. Nämä ovat tutkijoita ja teoksia, joiden voi katsoa vaikuttaneen ennen kaikkea Leninin teoreettisen ajattelun kehitykseen. Hobsonilta on peräisin ajatus pääomien viennistä ja koroillaaneläjävaltioista. Luxemburg ja Kautsky ovat sen sijaan vaikuttaneet lähinnä negatiivisina esimerkkeinä: Leninin suhde heihin on vahvan poleeminen ja kriittinen. ${ }^{8}$

Ehkä kaikkein tärkein ja samalla problemaattisin on kuitenkin Leninin Imperialismiteoksen suhde Hilferdingin Das Finanzkapitaliin. Hilferdingin vaikutus vuosisadan alun marxilaiseen tutkimukseen ja keskusteluun on kaiken kaikkiaan ollut merkittävä. Jo ennen Das Finanzkapitalia Hilferding oli saavuttanut kuuluisuutta Marx-tutkijana osallistumalla kirjoituksellaan "Böhm-Bawerks MarxKritik"9 keskusteluun ns. transformaatioprobleemasta, joka oli aktualisojtunut Marxin Pääoman III osan ilmestyttyä vuonna 1894 ja joka koski arvojen ja hintojen suhdetta Pääomassa. Das Finanzkapitalin merkitystä kuvaa se, että pian sen ilmestyttyä Karl

7. LV, osa 2. s. 287 , ks. myös Rozental, M. M. Dialektika leninskogo issledovanija imperializma i revolutsii. Moskva 1976, s. 141-142.

8. Lenin ei käsittele Luxemburgin teosta lainkaan Imperialismi-teoksessaan. Leninin muistiinpanojen perusteella tiedetään kuitenkin, että Lenin pitì Luxemburgin käsitystä imperialismista virheellisenä ja suunnitteli erillistä kirjoitusta, jossa olisi osoittanut tämän (ks. Leontjew, mt.s. 87).

9. Hilferding, Rudolf, Böhm-Bawerks Marx-Kritik. Teoksessa Eberle, Friedrich (hrsg.), Aspekte der Marxschen Theorie 1. Zur methodischen Bedeutung des 3. Bandes des "Kapital". Suhrkamp, Frankfurt am Main 1973. (Ilmestyi alunperin teoksessa Marx-Studien, hrsg. von M. Adler und R. Hilferding, Erster Band, Wien 1904). 
Kautsky kiirehti julistamaan sen Pääoman neljänneksi osaksi. ${ }^{10}$ Voimakkaita vaikutteita Das Finanzkapitalista on nähtävissä niin Kautskyn, Bernsteinin, Buharinin kuin Lenininkin imperialismi-analyyseissa. Leninin Imperialismiteoksen ilmestyttyä monet kriitikot julistivatkin, että Lenin esittää teoksessaan vain populaarisessa muodossa uudelleen Hilferdingin Das Finanzkapitalin. 11

Pinnallinenkin tarkastelu riittää osoittamaan, että Leninin ja Hilferdingin teoksista löytyy paljon yhteistä. Niin Leninin monopolin, kartellin kuin finanssipääomankin käsittely näyttää olevan paljossa velkaa Hilferdingille. Ehkä helpoimmin havaittava ero teosten välillä on se, että kun Leninin ensisijaisena tarkastelukohteena on kapitalistinen maailmantalous, Hilferding ei sen sijaan käsittele juuri lainkaan maailmanmarkkinoita ja kansainvälistä kilpailua. Leninin kirjoittama ensimmäinen Imperialismi-teoksen sisällyssuunnitelma muistuttaa Hilferdingin teoksen rakennetta (tällöin Lenin suunnitteli kirjastaan vielä lähinnä Kaustky-kritiikkiä 12). Valmiissa teoksessa lukujen järjestys on jo toinen: pankpien käsittelyä edeltää keskittymisen ja monopolien käsittely.

Lenin piti Hilferdingiä marxilaisena tutkijana eikä juuri esittänyt Hilferdingin teoreettisten näkökantojen ja käsitteiden eksplisiittistä kritiikkiä.13 Leninin muistiinpanoissa, jotka koskevat Das Finanzkapitalia, esitetään lähinnä teoksen sisällysluettelo ja lyhyt yhteenveto, jota ei kommentoida. ${ }^{14}$ Tiedetään kuitenkin, että Lenin piti Hilferdingin rahateoriaa virheellisenä ("Hilferdingillä raha tulee kiertoon ilman arvoa'), mutta Lenin ei kehitellyt tätä kritiikkiä sen pidemmälle. Imperialismi-teoksessa Lenin arvostelee Hilferdingiä lähinnä siitä, että tämä määrittelee finanssipääoman ottamatta huomioon, että kyse on monopolisoituneesta pääomasta. Heti tämän jälkeen Lenin kuitenkin toteaa, että Hilferding on juuri ennen finanssipääomaa itse asiassa käsitellyt keskittymistä ja kartelleja. ${ }^{15}$

\section{2.}

Hilferdingin mukaan "modernin" kapitalismin luonteenomaisin piirre ovat ne keskittymistapahtumat, jotka ilmenevät toisaalta "vapaan kilpailun kumoutumisena" kartellien ja trustien muodostumisen seurauksena, toisaalta yhä kiinteämpinä pankki- ja teollisuuspääomien välisinä suhteina. Tämän suhteen kautta pääoma saa "finanssipääoman muodon, joka on sen korkein ja abstraktein ilmenemismuoto". 16 Tutkimuksessaan Hilferding tulee siihen tulokseen, että kartellien muodostumiselle ei ole mitään esteitä. Keskittymiskehitys johtaakin lopulta yleiskartelliin: "Paremminkin vallitsee tendenssi jatkuvaan kartellisoitumisen leviämiseen. (...) Tämän tendenssin tuloksena syntyy yleiskartelli. Koko kapitalistista tuotantoa ohjataan tietoisesti instanssista, joka määrittää tuotannon laajuuden kaikilla aloilla. Silloin hintojen määräämisestä tulee puhtaasti nimellistä ja se merkitsee enää kokonaistuotteen jakamista toisaalta kartellimagnaateille, toisaalta kaikkien yhteiskunnan jäsenten muodostamalle massalle. Hinta ei ole tällöin esineelli-

10. Kautsky, Karl, Finanzkapital und Krise. Neue Zeit, Bd. I, Stuttgart 1910, s. 765 ja 883.

11. Uudemmista tätä mieltä olevista kriitikoista mainittakoon David Horowitz (Imperialismus und Revolution, Neue Fakten zur gegenwärtigen Geschichte. Berlin 1970).

12. LT, osa 39, s. $91,206-218$.

13. On syytä huomauttaa, että Leninin tuntema Das Finanzkapitalin Hilferding on vielä kaukana Weimarin tasavallan sosiaalidemokraattisesta poliitikko ja ideologi Hilferdingistä. Vaikka Das Finanzkapitalin "yleiskartellia" voidaan pitää Hilferdingin sosiaalidemokraattien puoluepäivillä vuonna 1927 esittämän "organisoidun kapitalismin" käsitteen itumuotona, ovat etenkin Hilferdingin poliittiset johtopäätökset erilaiset: kun Hilferding asetti aikaisemmin imperialismia vastaan vaihtoehdoksi sosialismin, niin myöhemmin organisoitu kapitalismi oli jo hänen mielestään tosiasiassa sosialismia.

14. Emt. s. $311-316$.

15. LV, osa 2. s. 366.

16. Hilferding, Rudolf, Das Finanzkapital. Europeische Verlagsanstalt, Frankfurt am Main 1968 (ilmestyi alunperin 1910), s. 17. 
sen suhteen tulos, johon ihmiset ovat joutuneet, vaan pelkkä laskennallinen tapa, jolla ihmiset jakavat esineet keskenään. Raha ei näyttele tällöin mitään roolia." 17 Finanssipääoma lakkauttaa pääoman erityisen luonteen. Yleiskartellin hallitsema yhteiskunta olisi tietoisesti ohjattu, mutta silti antagonistinen yhteiskunta. Tällaisen yleiskartellin kehittyminen on Hilferdingin mielestä taloudellisesti vaikkakaan ei poliittisesti mahdollista: "Sinänsä olisi sellainen yleiskartelli taloudellisesti ajateltavissa, joka johtaisi kokonaistuotantoa ja ylittäisi siten kriisit, joskin tällainen olisi sosiaalisesti ja poliittisesti mahdottomuus, koska se tulisi tuhoutumaan intressivastakkaisuuteen, jonka se kehittäisi huippuunsa." 18

On jokseenkin helppo löytää Leninin Imperialismi-teoksesta yksittäisiä kohtia, jotka viittaavat siihen, että Lenin hyväksyi Hilferdingin teoreettiset käsitykset jopa kapitalistista tuotantoa hallitsevaa yleiskartellia ja keskuspankkia myöten. Lenin näyttää luottavan Hilferdingin tavoin varsin paljon pankkien mahdollisuuteen hallita ja tietoisesti ohjata tuotantoa: 'Erillisestä kapitalistista muodostuu yksi kollektiivinen kapitalisti. (...) ilmeneekin, että kourallinen monopolisteja alistaa valtaansa koko yhteiskunnan kauppa- ja teollisuustoiminnan, sillä monopolisteille käy pankkiyhteyksien, juoksevien tilien ja muiden finanssioperaatioiden kautta - mahdolliseksi ensin saada tarkasti tietoonsa yksityisten kapitalistien asiat, sitten valvoa heitä, vaikuttaa heihin lisäämällä tai supistamalla luottoa, helpottamalla tai vaikeuttamalla sen saantia ja vihdoin kokonaan määrätä heidän kohtalostaan, määrätä heidän tulostaan, riistää heiltä pääoma tai sitten sallia heidän kartuttaa pääomaansa nopeasti ja voimakkaasti jne." 19

Lenin kirjoitti Buharinin teokseen Imperialismi ja maailmantalous esipuheen, jossa hän esittää oman käsityksensä "yleiskartellin" mahdollisuudesta. Se muistuttaa suuresti Hilferdingin käsitystä: "Voidaanko kuitenkaan väittää sitä vastaan, että abstraktisti on 'ajateltavissa' kapitalismin uusin vaihe imperialismin $\mathrm{j}$ ä $1 \mathrm{k}$ e e $\mathrm{n}$, nimittäin ultraimperialismi? Ei voida. Abstraktisti sellainen vaihe on ajateltavissa. (..) Ei ole epäilystäkään siitä, etteikö suuntana olisi yksi ainoa koko maailman käsittävä trusti, joka nielee poikkeuksetta kaikki valtiot. Mutta kehitys kulkee siihen suuntaan sellaisissa olosuhteissa, sellaista vauhtia, sellaisten ristiriitojen, selkkausten ja järistysten oloissa - eikä suinkaan vain taloudellisten, vaan myös poliittisten, kansallisten y.m. y.m., - että e n n e n kuin päädytään yhteen maailmantrustiin, kansallisten finanssipääomien 'ultraimperialistiseen' yleismaailmalliseen yhtymään imperialismi on ehdottomasti romahtava ja kapitalismi muuttuva omaksi vastakohdakseen." 20 Kuten havaitaan käsitysten samankaltaisuudesta huolimatta Leninin käsitys eroaa Hilferdingin esittämästä ainakin yhdessä tärkeässä suhteessa: Lenin puhuu - poliittisten ristiriitojen ohella - $\mathrm{t}$ a 1 o u d e 11 is is $\mathrm{t}$ a ristiriidoista, jotka muuttavat kapitalismin vastakohdakseen ennen kuin se on ehtinyt kehittyä "ultraimperialismiksi". Hilferding sen sijaan näyttää pitävän tällaista kehitystä taloudellisesti mahdollisena. Juuri tällaista ajattelua Lenin kutsuu "abstraktiksi".

\section{3.}

Leninin ja Hilferdingin monopolikapitalismia koskevien käsitysten kannalta on keskeinen kysymys se miten he ajattelevat monopolin syntyvän ja mikä on monopolin suhde kilpailuun ja vapaaseen kilpailuun. Hilferdingin mukaan kartellien syntyminen on seurausta pääomien välisen kilpailun esteistä, jotka muodostuvat siirryttäessä suurtuotantoon. ${ }^{21}$

17. Emt., s. $321-322$.

18. Emt., s. $402-403$.

19. LV, osa 2 , s. 356.

20. LT, osa 22 , s. $97-98$.

21. Esitettävä Hilferdingin käsitys kartellin synnystä on tiivistelmä Hilferding, emt., s. 246-281. 
Jokainen kilpaileva pääoma pyrkii saamaan lisävoiton, keskimääräistä korkeamman voiton. Pääomien välinen kilpailu tuottaa kuitenkin tulokseksi objektiivisen tendenssin, keskimääräisen voittosuhteen muodostumisen. Tämän pääomien alalta toiselle tapahtuvan virtaamisen tielle, joka toteuttaa keskimääräisen voittosuhteen, syntyy kasvavia esteitä kapitalismin kehittyessä. Työn yhteiskunnallisen tuotantovoiman kasvu johtaa pääoman orgaanisen kokoonpanon kasvuun ja erityisesti kiinteän pääomanosan kasvuun. Samalla kasvavat tuotannon mittasuhteet ja kullakin alalla tuotannon aloittamiseksi tarvittava pääomamäärä kasvaa. Sijoitettavan pääoman suuruus ei kuitenkaan Hilferdingin mukaan sinänsä vaikeuta pääoman virtaamista alalta toiselle koska samalla syntyvät pääoma-assosiaatiot (lähinnä: osakeyhtiöt), jotka pystyvät mobilisoimaan tarvittavan suuruiset pääomat. Sen sijaan pääoman siirtyminen niiltä ajoilta pois, joilla kiinteän pääoman osuus on suuri ja joilla Hilferdingin mukaan voittosuhde on alhainen, tulee vaikeaksi. Näillä aloilla voi tapahtua sijoitetun pääoman vähentymistä vain siten, että vanhat tuotantolaitokset lakkaavat vähitellen toimimasta tai pääoma tuhoutuu kokonaan vararikoissa.

Seurauksena pääoman liikkumisen uusista esteistä on se, että voittosuhde pyrkii pienenemään kapitalistisen tuotannon kummassakin "ääripäässä": sekä suurteollisuudessa, missä kiinteän pääoman osuus on suuri, että pientuottajien hallitsemilla aloilla. Voittosuhteen pieneneminen aloilla, joilla kiinteän pääoman osuus on suuri, synnyttää kartellit. Kartellit ovat kaikkien alalla toimivien yhtiöiden intressissä, sillä kaikki häviävät kilpailun takia. Kartelli lakkauttaa kilpailun ja tekee siten mahdolliseksi keskimääräistä voittosuhdetta korkeamman voiton. Erityisesti pankit suosivat kartellien syntymistä, sillä ne ovat sijoittaneet lainapääomaa moniin samalla alalla toimiviin yhtiöihin.
4.

Kilpailu on Marxin Pääomassa kapitalismin sisäisten lakien välttämätön toteutumismuoto, jonka kautta kapitalistisen tuotannon immanentit lait toteutuvat ulkoisina pakkolakeina suhteessa yksittäisiin kapitalisteihin. ${ }^{22}$ Kilpailun tieteellinen analyysi on Marxin mukaan mahdollista vasta sitten kun on käsitetty pääoman "sisäinen luonto". Pääoman III osassa Marx esittää miten "kilpailun pakkolait" toteuttavat kullekin tuotannonalalle tuotantohinnan ja keskimääräisen voittosuhteen. Pääoman esitystapaan ei sen sijaan sisälly lainkaan kilpailun varsinaisten konkreettis-historiallisten ilmenemismuotojen tarkastelua ("Preiskonkurrenz"; markkinahintojen heilahtelujen esitys). Tutkittaessa monopolin asemaa kapitalistisen tuotantotavan kehityksessä ongelmana on sen suhde kilpailuun lakien välttämättömän toteutumismuodon merkityksessä ja erityisesti vapaaseen kilpailuun: onko monopoli vain kilpailun konkreettis-historiallinen ilmenemismuoto vai onko monopolistinen kilpailu samalla tavalla pääoman sisäisten lakien välttämätön toteutumismuoto kuin vapaa kilpailu.

Eräät Leninin modernit kriitikot ovat väittäneet, että Lenin ei olisi käsittänyt kilpailua pääomaan perustuvan tuotantotavan välttämättömäksi toteutumismuodoksi, vaan tarkastelee kilpailua vain sen konkreettis-historiallisissa ilmenemismuodoissaan. Niinpä Lenin voikin kriitikoiden mukaan ajatella monopolin voivan syrjäyttää kilpailun imperialismin kaudella (joskin kilpailu säilyy - tosin uudes-

22. Ks. esim. Marx, Karl, Das Kapital. Krtik der politischen Ökonomie. Erster Band. Dietz Verlag, Berlin 1969, s. 286 ja 335). Grundrissessä Marx toteaa: "Kilpailu on ylipäätään tapa, jolla pääoma toteuttaa tuotantotapansa." (Marx, Karl, Grundrisse der Kritik der politischen Ökonomie. Frankfurt am Main-Wien, ei painovuotta. s. 617). 
sa muodossa - maailmanmarkkinoilla). ${ }^{23}$

Hilferdingin Das Finanzkapitalin suhteen Leninin modernien kriitikkojen väitteet todella monessa suhteessa pitävät paikkansa. Reinhard Schimkowsky on kritisoinut Hilferdingiä $\mathrm{mm}$. siitä, että tämä tarkastelee kilpailua vain sen konkreettis-historiallisessa ilmenemismuodossaan eikä näe kilpailua pääoman liikkeen välttämättömänä toteutumismuotona. Tämä johtaa Hilferdingin absolutisoimaan pääoman tiellä olevia esteitä ja niistä syntyviä kartelleja, jotka voivat siten lakkauttaa kokonaan kilpailun. Kilpailu kapitalismin sisäisten lakien toteuttajana korvautuu pääomanomistajien välisillä herruussuhteilla. ${ }^{24}$

Schimkowskyn Hilferding-analyysi on mielenkiintoinen mutta hieman pinnallinen. Hilferdingin perusvirhe ei nimittäin oikeastaan ole, ettei hän ymmärrä kilpailun asemaa Marxin Pääomassa, tai että hän tarkastelee vain kilpailun konkreettis-historiallisia ilmenemismuotoja, vaan ennen kaikkea, ettei hän oikeastaan tarkastele missään järkevässä mielessä kilpailua lainkaan. Eikä hän voi tätä omista lähtökohdistaan lainkaan tehdäkään.

Hilferdingin kapitalismikonstruktiota hallitsee - kuten usein on todettu - kierron sfääri (vrt. yhteys virheelliseen rahateoriaan); kierto on Hilferdingille ensisijainen, tuotanto toissijainen. ${ }^{25}$ Esimerkiksi Cora Stephan on osoittanut, että Hilferdingin tuotantoprosessi on vain työprosessi, ja pääomasuhde esiintyy siten vain vaihdon piirissä. ${ }^{26}$ Pääomien välisen kilpailun tarkastelussa "kierron ensisijaisuus" tulee esille siten, että Hilferding ei itse asiassa lainkaan tarkastele varsinaista tavaroita tuottavien pääomien, vaan ainoastaan lainapääomien välistä kilpailua: juuri lainapääoma siirtyy voittosuhteen suuruuden mukaan alalta toiselle. Pääoman vapaan liikkeen tiellä olevia esteitä Hilferding taas tarkastelee vain tuotantoprosessin aineellisen puolen kannalta. $\mathrm{Ku}-$ vaavaa on, että Das Finanzkapitalissa ei esiinny lainkaan markkina-arvoa tai kustannushin- taa alojen välisen kilpailun perustana, eikä keskimääräinen voittosuhde toteuta kullekin alalle tuotantohintaa. Kilpailun tuloksena lainapääoma vain siirtyy alalta toiselle, jolloin alalla tuotettu voittomassa joudutaan jakamaan suuremman tai pienemmän lainapääomamassan kesken. Kuvaavaa Hilferdingin käsitykselle pääomien liikkeestä on $\mathrm{mm}$. seuraava osakeyhtiöitä luonnehtiva kohta: "... pääoman mobilisointi jättää luonnollisesti tuotantoprosessin koskemattomaksi. Se koskettaa nyt vain omaisuutta, luo vain muodon kapitalistisesti toimivan omaisuuden siirrolle pääomana, voittoa siittävänä rahasummana. Koska se jättää tuotannon koskematta, tämä siirto on itse asiassa vain voittoon liittyvän omaisuusnimikkeen siirto". ${ }^{27}$

\section{5.}

Imperialismi-teos on Leninin omien sanojen mukaan "yleistajuinen" esitys, jossa pyritään näyttämään "kiistattomien porvarillisten ti-

23. Neusüss, Christel, Imperialismus und Weltmarktbewegung des Kapitalis, Erlangen 1972, s. 30. Tämän Lenin "virheen" on katsottu olevan yhteydessä siihen, että Lenin ei olisi ymmärtänyt oikein Pääoman esitystavan yleisyysastetta, vaan olisi käsittänyt sen kapitalismin tietyn historiallisen vaiheen kuvaukseksi. Leninin pyrkimys kehittää "Marxin taloudellisia katsomuksia siten, että ne vastaavat talouselämän uusimpia ilmiöitä" (LV; osa 2. s. 335) olisi ymmärrettävä tämän perusteella. (ks. esim. Projekt Klassenanalyse, Leninismus - eine neue Stufe des wissenschaftlichen Sozialismus? VSA, Westberlin 1972, s. 373-374 ja Jordan, Dirk, Der Monopolbegriff im System der Kritik der politischen Ökonomie. Teoksessa Ebbighausen, Rolf (hrsg.), Monopol und Staat. Zur Marx-Rezeption in der Theorie des staatsmonopolistischen Kapitalismus. Suhrkamp, Frankfurt am Main 1974, s. 214).

24. Schimkowsky, Reinhard, Zur Marx-Rezeption bei Hilferding. Die Bestimmungen von Konkurrenz und Monopol im "Finanzkapital". Teoksessa Ebbighausen, Monopol und Staat, emt.

25. Esim. Leontjev, mt. s. 80-81.

26. Stephan, Cora, Geld- und Staatstheorie in Hilferdings "Finanzkapital". Zum Verhältnis von ökonomischer Theorie und politischer Strategie. Teoksessa Gesellschaft. Beiträge zur Marxschen Theorie 2. Suhrkamp, Frankfurt am Main 1974, s. 140.

27. Hilferding, emt. s. 252. 
lastoyhteenvetojen ja kaikkien maiden porvarillisten tiedemiesten lausuntojen perusteella, minkälainen oli kapitalistisen maailman kokonaiskuva sen kansainvälisten keskinäissuhteiden kannalta katsoen 20. vuosisadan alussa, ensimmäisen imperialistisen maailmansodan aattona". ${ }^{28}$ Teoksen luonteesta johtuen Lenin ei asettanut tehtäväkseen esittää seikkaperäisesti kapitalismin sisäisten lakien toteutumistapaa monopolikapitalismin kaudella. Kuten esimerkiksi Günter Krause on todennut tämä ei johtunut siitä, etteikö Lenin olisi pitänyt tätä tehtävää tärkeänä, vaan siitä että Leninin kirjan tehtävänä oli ensi sijassa kehittää vallankumouksellisen liikkeen strategiaa ja taktiikkaa vastaamaan muuttuneita yhteiskunnallisia olosuhteita. ${ }^{29}$ Tämän takia Lenin ei pyri esimerkiksi osoittamaan millä tavoin monopolit todellisuudessa modifioivat kilpailua ja miten monopolihinnat ja -voitot määräytyvät. Lenin pyrkii esittämään vain imperialismin keskeiset erikoispiirteet, jotka hän johtaa monopoleista.

Leninin teoksen luonteesta johtuen Leninin monopolipääomaa koskevien käsitysten tulkitseminen on eräiltä osin vaikeaa. Leninin mukaan esimerkiksi monopoli ei lakkauta vapaata kilpailua, vaan esiintyy sen yläpuolella ja rinnalla. Imperialismi-teoksessa on suoranainen kohta, joka viittaa siihen, että Lenin käsitti täysin kilpailun luonteen kapitalismin sisäisten lakien toteuttajana: "Vapaa kilpailu on kapitalismin ja tavaratuotaænon perusominaisuus yleensä ..." Monopoli ei siis Leninin mukaan voi lakkauttaa pääomien välistä kilpailua. Ongelmallista on sen sijaan se, mitä Lenin tarkoittaa sillä, että monopoli ei myöskään lakkauta vapaata kilpailua, vaan esiintyy sen rinnalla. Ristiriita monopolien ja niiden rinnalla tapahtuvan vapaan kilpailun välillä on Leninin mukaan kaiken lisäksi eräs imperialismin syvimmistä perusristiriidoista. ${ }^{30}$ Ongelman voi tulkita johtuvan Leninin esitystavasta: Lenin ei toe tarkkaa eroa kilpailun yleensä ja sen eri muotojen, vapaan kilpailun ja monopolistisen kilpailun, välillä. Tämä on yhteydessä siihen, että Lenin tarkastelee monopolia varsin usein konkreettisesti ja samaistaa sen monopolin erilaisiin juridisiin ilmenemismuotoihin: kartelliin, syndikaattiin ja trustiin. Tällä tarkastelutasolla voidaan puhua siitä, että monopolit hallitsevat joitakin tuotannonaloja, kun taas muilla aloilla vallitsee "vapaa kilpailu". On kuitenkin ilmeistä, että niilläkään aloilla joilla ei esiinny "monopoleja" kilpailu ei säily entisen kaltaisena vapaana kilpailuna, vaan monopolien synty vaikuttaa esimerkiksi hintojen ja voittojen määräytymiseen näilläkin aloilla. Jos halutaan esittää systemaattisesti monopolihintojen ja -voittojen muodostumista säätelevät kilpailun lait, monopolia onkin tarkasteltava erityisenä kilpailun muotona, monopolistisena kilpailuna, joka syrjäyttää vapaan kilpailun, vaikkei lakkautakaan pääomien välistä kilpailua.

Imperialismi-teokseen liittyvistä tulkintaongelmista huolimatta voidaan aivan varmasti sanoa, että Leninillä kilpailun käsite on selvästi erilainen kuin Hilferdingillä. Ehkä kaikkein selvimmin tämä tulee esille kirjoituksessa "Puolueen ohjelman tarkistusaineistoa", joka on kirjoitettu Imperialismi-teoksen ilmestymisaikoihin, keväällä 1917: "Nykyisessä sanamuodossaan ohjelman yleinen osa sisältää kapitalismin tärkeimpien ja oleellisimpien erikoisuuksien luonnehtimisen ja erittelyn yhteiskunnallis-taloudellisena järjestelmänä. Imperialismi, finanssipääoman aikakausi, e i o l e muuttanut perusteellisesti näitä erikoisuuksia. Imperialismi on kapitalismin kehityksen jatkoa, kapitalismin korkein vaihe - tietyssä suhteessa - sosialismiin johtava siirtymävaihe. Sen vuoksi en voi myöntää 'mekaanisek-

28. LV, osa 2. s. 335 .

29. Krause, Günter, Die linksopportunistische "Kritik" des marxistisch-leninistischen Monopolverständnisses. Wirtschaftswissenschaft 7, 1976, s. 1021.

30. LV, osa 2. s. 397, 398, 406, 421. 
si' sitä lisäystä, kun kapitalismin yleensä peruserikoisuuksien analyysiin lisätään imperialismin analyysi. Todellisuudessa imperialismi ei rakenna eikä voi rakentaa u ude st a a n kapitalismia alhaalta ylös asti. Imperialismi tekee kapitalismin ristiriidat yhä monimutkaisemmiksi ja kärjistää niitä, 'sotkee' monopolin vapaan kilpailun kanssa, mutta ei voi poistaa vaihtoa, markkinoita, kilpailua, kriisejä jne. Imperialismi on viimeisiä aikojaan elävää, mutta ei aikansa elänyttä kapitalismia, kuolevaa mutta ei kuollutta kapitalismia. Ei puhtaita monopoleja vaan monopoleja vaihdon, markkinoiden, kilpailun ja kriisien rinnalle, - se on imperialismin olennaisin erikoisuus." 31

Koska Leninin käsitys kapitalismista, kapitalismin uudesta vaiheesta ja kilpailun asemasta kapitalismissa on toisenlainen kuin Hilferdingin, ei Lenin voinut myöskään hyväksyä Hilferdingin (ja Buharinin) monopolin käsitettä. Tähän perustuen on mahdollista ratkaista Hilferdingin Das Finanzkapitalin ja Leninin Imperialismi-teoksen välinen suhde. Sekä Lenin että Hilferding tutkivat samoja kapitalismin uusia ilmiöitä, teollisuuden ja pankkien keskittymistä, ja käyttävät osittain samoja termejä, mutta kummallakin on oma käsityksensä näiden uusien ilmiöiden merkityksestä ja asemasta kapitalismin kehityksessä. Erilaisten käsityskantojen perustana on se, että Leninin poliittisen taloustieteen konseptio poikkeaa jyrkästi Hilferdingin käsityksestä, vaikka tämä ei estäkään Leniniä sijoittamasta omaan konseptioonsa joitakin Hilferdingin "tuloksia".

31. LT, osa 24. s 460 (alleviivaukset Leninin; kirjoittaja on tehnyt eräitä tarkistuksia käännökseen). 